\title{
Characteristics and consequences of medical care interruptions in HIV-infected patients in France
}

\author{
L. CUZIN ${ }^{1 *}$, P. DELLAMONICA ${ }^{2}$, Y. YAZDANPANAH ${ }^{3}$, S. BOUCHEZ $^{4}$, \\ D. REY ${ }^{5}$, B. $\mathrm{HOEN}^{6}$ AND A. CABIE ${ }^{7}$ for the Dat'AIDS Study Group $\dagger$ \\ ${ }^{1}$ INSERM, UMR 1027, Toulouse, France; Université de Toulouse III, Toulouse, France; CHU Toulouse, \\ COREVIH Midi Pyrénées Limousin, France \\ ${ }^{2}$ Infectious Diseases Unit, Nice University Hospital, France \\ ${ }^{3}$ Infectious and Tropical Diseases Unit, Bichat Hospital, Paris, ATIP-AVENIR Inserm U1137, Paris Diderot \\ University, Paris, France \\ ${ }^{4}$ Infectious Diseases Unit, Nantes University Hospital, France \\ ${ }^{5}$ HIVIAIDS Center, Strasbourg University Hospital, France \\ ${ }^{6}$ Infectious Diseases Unit, Pointe à Pitre University Hospital, French West Indies \\ ${ }^{7}$ Infectious Diseases Unit, Fort de France University Hospital, French West Indies
}

Received 7 April 2015; Final revision 10 February 2016; Accepted 7 March 2016; first published online 1 April 2016

\section{SUMMARY}

To describe the consequences of medical care interruptions (MCIs) we selected patients with at least two medical encounters between January 2006 and June 2013 in the Dat'AIDS cohort. Patients with any time interval $>15$ months between two visits were defined as having a MCI, as opposed to uninterrupted follow-up (UFU). Patients' characteristics at the time of HIV diagnosis and at the censoring date were compared between groups. Cox proportional hazards models were built to assess the role of interruptions on survival (total and AIDS-free). Of 11116 patients, 824 had at least one MCI. These patients were younger at the time of HIV diagnosis (30 vs. 33 years, $P<0 \cdot 0001)$. MCI was less frequent in men having sex with men $v s$. heterosexual patients [odds ratio (OR) $0 \cdot 81,95 \%$ confidence interval (CI) 0.69-0.96)], and a centre effect was described. MCI was independently associated with AIDS (OR 2.54, 95\% CI 2.10-3.09) and death (OR 2.65, 95\% CI 1.94-3.61). At the censoring date, $52.2 \%$ of patients with at least one MCI had viral load below detection vs. $85.3 \%$ of the UFU group $(P<0 \cdot 0001)$. In conclusion, MCIs were associated with patients' survival and with the proportion of viral loads below detection in our cohort, compromising individual and collective treatment benefits.

Key words: AIDS-free survival, care retention, HIV, lost to follow-up, virological control.

\section{INTRODUCTION}

On an individual level, linkage and retention to care are known to be critical for HIV-infected patients [1]. At the population level, this will allow a decrease

\footnotetext{
* Author for correspondence: Miss L. Cuzin, COREVIH, Batiment Turiaf, Hopital Purpan, TSA40031, 31059 Toulouse cedex, France. (Email: cuzin.1@chu-toulouse.fr)

$\dagger$ Members of the Dat'AIDS Study Group are given in the Appendix.
}

in the community viral load (VL) and consequently a decrease in HIV transmission [2-4]. The Centers for Disease Control and Prevention estimated that the proportion of virologically suppressed individuals in HIV-diagnosed patients in the USA was 35\% [5], mainly due to issues such as access to care, or adherence to care and treatment. Access to care is highly dependent on the healthcare system, and very different estimations have been made in countries with large 
and free access to care and treatment in Europe and in France [6, 7].

One of the key steps on the road from infection to durable virological suppression is adherence to care. Incidence rate of lost-to-follow-up (LTFU) has been estimated in Europe to be around 4/100 person-years, with significant differences between the European regions [8]. Age, absence of prescribed anti-retroviral therapy (ART), detectable VL while receiving therapy, intravenous drug use, CD4 cell counts, and time since HIV diagnosis have been shown to be associated with higher risks of LTFU in various studies [8-10].

Due to the unavoidable fatal outcome of HIV infection in the absence of treatment, those patients are due to return to care at some time after care interruption. The consequences of medical care interruptions (MCIs) have not been studied in recent years. In a recent study people known to be HIV-positive but not seeking care for their infection accounted for as much as 53\% of new opportunistic infections [11]. At the public health level, where it is desirable to have as many HIV-infected patients as possible with a VL below detection, MCIs are challenging if they result in more patients having a detectable VL even after they resume care.

The objective of this study was to describe the characteristics of patients who had had at least one MCI during their follow-up, and the individual and collective consequences of these interruptions.

\section{METHODS}

Information was collected from seven HIV reference centres in France that maintain prospective databases of all HIV-infected patients who sought care and provided written consent [12]. The databases collect demographic, clinical, antiretroviral history, VL, and CD4 cell count data at regular 3- to 6-month intervals during routine clinical assessment. Patients who changed facility during their follow-up are counted only once, i.e. in the last facility they attended. For the purpose of this study, we selected all patients with at least two clinical assessments registered in the database between 1 January 2006 and 30 June 2013. All data were censored on 30 June 2013.

Patients who had at least one time interval of $>15$ months between two visits were defined to have at least one MCI, as opposed to the remaining patients who had uninterrupted follow-up (UFU). The time gap of 15 months was chosen because French recommendations imply a hospital visit at least once a year, with possible intermediate clinical visits to a general physician [13]. We considered that patients presenting with a VL below detection level at the return-to-care visit could have been receiving care elsewhere during the considered interruption, they were therefore not considered in the study. MCI patients with missing data regarding CD4 or VL at the time of care interruption or at the time of care resumption were excluded. They were compared to patients with at least one MCI in order to identify a possible bias due to their exclusion.

Patients' characteristics at their inclusion in the database: age at HIV diagnosis, sex, most probable route of infection, hepatitis $\mathrm{B}$ or $\mathrm{C}$ co-infection, year of HIV diagnosis and the centre providing care were compared between the two groups.

At the end of the study period proportions of patients receiving ART, CDC classification, proportions of patients with VL below detection, vital status, cause of death, CD4 cell counts, AIDS-free and overall survival were also compared between the two groups.

Of patients with at least one MCI, duration of MCI, year of interruption, duration of known infection at the time of MCI, CD4 and VL values before and after MCI, prescribed ART before and after MCI, and new AIDS-defining events were described. As having a VL below detection (50 copies $/ \mathrm{ml}$ ) can be considered an indicator of efficient care, the characteristics were also described in patients with a VL below detection at the time of care interruption and in those without.

Categorical data were described by percentages and compared by $\chi^{2}$ method, continuous data were described by medians and interquartile range (IQR), and their distributions were compared between groups using Kruskal-Wallis non-parametrical tests. All individual characteristics associated with care interruption $(P<0 \cdot 1)$ were included in a multivariable logistic regression model in order to estimate independent associations. Mean times from HIV diagnosis to a first AIDS-defining event and to death were estimated by Kaplan-Meier methods. Cox proportional hazards models were built to assess the potential effect of care interruptions on the occurrence of AIDS or death in addition to baseline characteristics as fixed covariables. As a MCI may occur before or after the first AIDS-defining event, MCIs were treated as timedependent variables in the model built to assess the potential effect of care interruptions on occurrence 
of AIDS [14]. $\mathrm{MCI}(t)$ took the value 0 in the case of UFU and in case of MCI if the MCI occurred after the first AIDS-defining event; and the value 1 if MCI occurred before the first AIDS-defining event. In the Cox model built to assess the potential effect of care interruptions on death, MCI took the value 0 before the occurrence of a MCI and 1 afterwards. All statistics were performed using SAS v. 9.4 (SAS Institute Inc., USA).

\section{RESULTS}

Of the 16205 patients included in the cohort, 12014 had had at least two clinical visits during the study period. Of these, 10292 patients were classified as having UFU, and 1722 had at least one time interval between two clinical visits $>15$ months. Of those, 721 were not taken into consideration because of VL below detection at the first back-to-care visit. Of the patients with at least one MCI, 177 were excluded because of missing values either for CD4 cell counts or $\mathrm{VL}$ at the time of interruption or at the back-to-care visit. Thus the population of patients with at least one MCI included 824 patients, be compared to the 10292 with UFU (Fig. 1). Comparisons between excluded patients and patients with at least one MCI regarding sex, age at HIV diagnosis, presence of viral hepatitis co-infection, most probable route of infection, and vital status at the end of the study did not show any difference.

Comparisons between UFU and MCI patients and the regression results appear in Table 1. The MCI patients were significantly younger than UFU patients at the time of HIV diagnosis (median 30 vs. 33 years, $P<0.0001$ ), with a lower risk of MCI with increasing age. The most probable route of infection was associated with MCI, men who have sex with men having a lower risk [odds ratio (OR) $0 \cdot 81,95 \%$ confidence interval (CI) 0.69-0.96] compared to heterosexual patients. Some differences also appeared between the centres in which individuals sought care, one centre having a significant independent association with MCI (OR 1·54, 95\% CI 1·10-2·10). Median length of known infection was not different between groups.

At the end of the study period, compared to UFU patients, patients with at least one MCI were receiving ART less frequently $(91 \cdot 5 \% v s .97 \%$, respectively, $P<$ $0 \cdot 0001$ ), were more frequently classified as AIDS cases ( $32 \%$ vs. $24 \cdot 3$, respectively, $P<0 \cdot 0001$ ), and a greater proportion of patients had detectable VL $(47 \cdot 8 \% v s$.

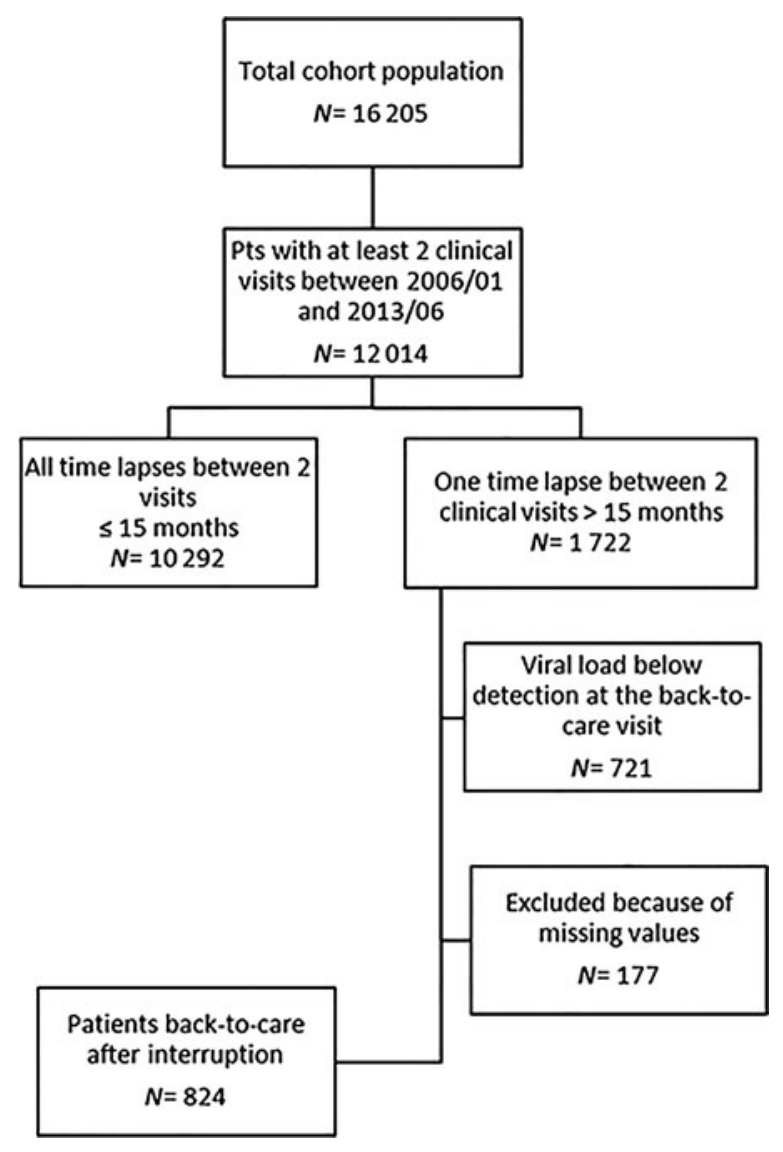

Fig. 1. Selection of patients from the cohort.

$14 \cdot 7 \%$, respectively, $P<0 \cdot 0001)$. All the comparisons are shown in Table 2.

A first AIDS-defining event was reported in 91 patients after care resumption. In 53 cases this event was the very reason to return to care (date of event $<1$ month after the back-to-care visit). Those 53 cases included mostly avoidable opportunistic infections: pneumocystis pneumonia (12 cases), cerebral toxoplasmosis (seven cases), profound candidiasis (six cases), cryptococcosis (six cases), progressive multifocal leukoencephalopathy (five cases), AIDS dementia (four cases), tuberculosis (three cases), lymphomas (two cases), cytomegalovirus infection (one case), Kaposi's sarcoma (two cases), and multiple infections (four cases). The 38 other first AIDS-defining events occurred later: median time 10 months (IQR 7-26). They included: pneumocystis pneumonia (seven cases), profound candidiasis (six cases), tuberculosis (five cases), Kaposi sarcoma (five cases), lymphomas (four cases), cytomegalovirus infection (three cases), cerebral toxoplasmosis (three cases), AIDS dementia (two cases), multiple infections (two cases) and progressive multifocal leukoencephalopathy (one case). 
Table 1. Patients' characteristics at inclusion in the cohort, univariate and multivariate risk ratios for medical care interruption

\begin{tabular}{|c|c|c|c|c|c|c|c|c|}
\hline & \multirow[b]{2}{*}{ Total $(N=11116)$} & \multirow[b]{2}{*}{$\mathrm{UFU}(N=10292)$} & \multirow[b]{2}{*}{$\operatorname{MCI}(N=824)$} & \multirow[b]{2}{*}{$P$} & \multicolumn{2}{|c|}{ Univariate } & \multicolumn{2}{|c|}{ Multivariate } \\
\hline & & & & & $\mathrm{RR}$ & $95 \% \mathrm{CI}$ & RR & $95 \% \mathrm{CI}$ \\
\hline Age at HIV diagnosis, years, median (IQR) & $33(26-41)$ & $33(26-42)$ & $30(25-38)$ & $<0.001$ & & & & \\
\hline$<27$ & & & & & Ref. & - & Ref. & - \\
\hline $27-34$ & & & & & $0 \cdot 78$ & $0 \cdot 66-0.94$ & $0 \cdot 72$ & $0 \cdot 59-0 \cdot 86$ \\
\hline $35-40$ & & & & & $0 \cdot 60$ & $0 \cdot 48-0 \cdot 73$ & $0 \cdot 49$ & $0 \cdot 39-0 \cdot 61$ \\
\hline$>40$ & & & & & $0 \cdot 47$ & $0 \cdot 39-0 \cdot 58$ & $0 \cdot 39$ & $0 \cdot 31-0 \cdot 48$ \\
\hline \multicolumn{9}{|l|}{ Sex, $n(\%)$} \\
\hline Women & $3363(30 \cdot 2)$ & $3118(30 \cdot 3)$ & $245(29 \cdot 7)$ & $0 \cdot 7$ & Ref. & - & & \\
\hline Men & $7753(69 \cdot 3)$ & $7174(69 \cdot 7)$ & $579(70 \cdot 3)$ & & $1 \cdot 02$ & $0 \cdot 88-1 \cdot 20$ & & \\
\hline \multicolumn{9}{|l|}{ Most probable route of infection, $n(\%)$} \\
\hline Heterosexual & $5088(45 \cdot 8)$ & $4691(45 \cdot 6)$ & $397(48 \cdot 2)$ & $0 \cdot 0004$ & Ref. & - & Ref & - \\
\hline Homosexual/bisexual & $4271(38 \cdot 4)$ & $4000(38 \cdot 9)$ & $271(32 \cdot 9)$ & & $0 \cdot 80$ & $0 \cdot 68-0 \cdot 94$ & $0 \cdot 87$ & $0 \cdot 74-1 \cdot 35$ \\
\hline Materno-fetal & $90(0 \cdot 8)$ & $84(0 \cdot 8)$ & $6(0 \cdot 7)$ & & $0 \cdot 84$ & $0 \cdot 36-0 \cdot 94$ & $0 \cdot 72$ & $0 \cdot 31-1 \cdot 69$ \\
\hline Blood products/IVDU & $1176(10 \cdot 6)$ & $1058(10 \cdot 3)$ & $118(14 \cdot 3)$ & & $1 \cdot 32$ & $1 \cdot 06-1 \cdot 64$ & $1 \cdot 41$ & $1 \cdot 07-1 \cdot 87$ \\
\hline Other/unknown & $487(4 \cdot 4)$ & $455(4 \cdot 4)$ & $32(3 \cdot 9)$ & & $0 \cdot 83$ & $0 \cdot 57-1 \cdot 31$ & $0 \cdot 94$ & $0 \cdot 64-1 \cdot 38$ \\
\hline $\begin{array}{l}\text { Duration of known HIV infection, years, } \\
\text { median (IQR) }\end{array}$ & $13(6-20)$ & $13(6-20)$ & $12(7-9)$ & $0 \cdot 97$ & & & & \\
\hline \multicolumn{9}{|l|}{ Year of HIV diagnosis, $n(\%)$} \\
\hline$<1993$ & $2814(25 \cdot 3)$ & $2645(25 \cdot 7)$ & $169(20 \cdot 5)$ & $<0 \cdot 0001$ & Ref. & & Ref. & - \\
\hline 1993-1999 & $2602(23 \cdot 4)$ & $2384(23 \cdot 1)$ & $218(26 \cdot 5)$ & & $1 \cdot 43$ & $1 \cdot 16-1 \cdot 76$ & $2 \cdot 02$ & $1 \cdot 61-2 \cdot 55$ \\
\hline $2000-2006$ & $3050(27 \cdot 4)$ & $2742(26 \cdot 7)$ & $308(37 \cdot 4)$ & & $1 \cdot 76$ & $1 \cdot 45-2 \cdot 14$ & $2 \cdot 80$ & $2 \cdot 23-3 \cdot 52$ \\
\hline$>2006$ & $2650(23 \cdot 9)$ & $2521(24 \cdot 5)$ & $129(15 \cdot 6)$ & & $0 \cdot 8$ & $0 \cdot 63-1 \cdot 01$ & $1 \cdot 32$ & $1 \cdot 01-1 \cdot 72$ \\
\hline \multicolumn{9}{|l|}{ Hepatitis co-infection, $n(\%)$} \\
\hline No & $8877(79 \cdot 8)$ & $8254(80 \cdot 2)$ & $623(75 \cdot 6)$ & $0 \cdot 002$ & Ref. & - & Ref & - \\
\hline Yes & $2239(20 \cdot 2)$ & $2038(19 \cdot 8)$ & $201(24 \cdot 4)$ & & $1 \cdot 31$ & $1 \cdot 11-1 \cdot 54$ & $1 \cdot 21$ & $0 \cdot 98-1 \cdot 49$ \\
\hline \multicolumn{9}{|l|}{ HIV care centre, $n(\%)$} \\
\hline A & $1004(9)$ & $932(9)$ & $72(8 \cdot 7)$ & $0 \cdot 002$ & Ref. & - & Ref. & - \\
\hline $\mathrm{B}$ & $986(8 \cdot 9)$ & $911(8 \cdot 9)$ & $75(9 \cdot 1)$ & & $1 \cdot 07$ & $0 \cdot 76-1 \cdot 49$ & $1 \cdot 16$ & $0 \cdot 82-1 \cdot 65$ \\
\hline $\mathrm{C}$ & $914(8 \cdot 2)$ & $822(8)$ & $92(11 \cdot 2)$ & & $1 \cdot 45$ & $1 \cdot 05-2 \cdot 00$ & $1 \cdot 60$ & $1 \cdot 15-2 \cdot 33$ \\
\hline $\mathrm{D}$ & $2365(21 \cdot 3)$ & $2209(21 \cdot 5)$ & $156(18 \cdot 9)$ & & $0 \cdot 91$ & $0 \cdot 68-1 \cdot 22$ & $0 \cdot 98$ & $0 \cdot 73-1 \cdot 32$ \\
\hline $\mathrm{E}$ & $2009(18 \cdot 1)$ & $1839(17 \cdot 9)$ & $170(20 \cdot 6)$ & & $1 \cdot 19$ & $0 \cdot 89-1 \cdot 59$ & $1 \cdot 20$ & $0 \cdot 90-1 \cdot 61$ \\
\hline $\mathrm{F}$ & $1639(14 \cdot 7)$ & $1542(15)$ & $97(11 \cdot 8)$ & & $0 \cdot 81$ & $0 \cdot 59-1 \cdot 12$ & $0 \cdot 83$ & $0 \cdot 61-1 \cdot 15$ \\
\hline G & $2199(19 \cdot 8)$ & $2037(19 \cdot 7)$ & $162(19 \cdot 7)$ & & $1 \cdot 03$ & $0 \cdot 77-1 \cdot 37$ & $1 \cdot 07$ & $0 \cdot 79-1 \cdot 45$ \\
\hline
\end{tabular}

IQR, Interquartile range; UFU, uninterrupted followed-up patients; MCI, patients with at least one medical care interruption; RR, risk ratio; CI, confidence interval; IVDU, intravenous drug user. 
Table 2. Patients' characteristics at the end of the study period

\begin{tabular}{|c|c|c|c|c|}
\hline & $\begin{array}{l}\text { Total, } N(\%) \\
{[11116(100)]}\end{array}$ & $\begin{array}{l}\text { UFU, } N(\%) \\
{[10292(92 \cdot 6)]}\end{array}$ & $\begin{array}{l}\text { MCI, } N(\%) \\
{[824(7 \cdot 4)]}\end{array}$ & $P$ \\
\hline \multicolumn{5}{|l|}{ Receiving ART, $n(\%)$} \\
\hline Yes & $10713(96)$ & 9959 (97) & $754(91 \cdot 5)$ & \multirow[t]{2}{*}{$<0 \cdot 000$} \\
\hline No & $403(4)$ & $333(3)$ & $70(8 \cdot 5)$ & \\
\hline \multicolumn{5}{|l|}{ CDC stage $\mathrm{C}, n(\%)$} \\
\hline Yes & $2766(24 \cdot 9)$ & $2502(24 \cdot 3)$ & $264(32)$ & \multirow{2}{*}{$<0 \cdot 0001$} \\
\hline No & $8350(75 \cdot 1)$ & $7790(75 \cdot 7)$ & $560(68)$ & \\
\hline \multicolumn{5}{|l|}{ Last VL below detection, $n(\%)$} \\
\hline Yes & $9197(82 \cdot 9)$ & $8777(85 \cdot 3)$ & $420(52 \cdot 2)$ & \multirow[t]{2}{*}{$<0.0001$} \\
\hline No & $1900(17 \cdot 1)$ & $1515(14 \cdot 7)$ & $385(47 \cdot 8)$ & \\
\hline \multicolumn{5}{|l|}{ Vital status, $n(\%)$} \\
\hline Alive & $10609(95 \cdot 4)$ & $9829(95 \cdot 5)$ & $780(94 \cdot 7)$ & \multirow[t]{2}{*}{$0 \cdot 26$} \\
\hline Dead & $507(4 \cdot 6)$ & $463(4 \cdot 5)$ & $44(5 \cdot 3)$ & \\
\hline \multicolumn{5}{|l|}{ Cause of death, $n(\%)$} \\
\hline AIDS related & $101(20)$ & $82(17 \cdot 7)$ & $19(43)$ & \multirow[t]{2}{*}{0.0007} \\
\hline Other & $406(80)$ & $381(82 \cdot 3)$ & $25(57)$ & \\
\hline \multicolumn{5}{|l|}{ Died with VL below detection, $n(\%)$} \\
\hline Yes & $320(63)$ & $305(66)$ & $15(34)$ & \multirow{2}{*}{$<0.0001$} \\
\hline No & $187(37)$ & $158(34)$ & $29(66)$ & \\
\hline Last $\mathrm{CD} 4$ cell count value, median (IQR) & $591(416-783)$ & $601(433-793)$ & $397(221-625)$ & $0 \cdot 0001$ \\
\hline
\end{tabular}

UFU, Uninterrupted followed-up patients; MCI, patients with at least one medical care interruption; ART, anti-retroviral therapy; VL, viral load; IQR, interquartile range.

Table 3. Characteristics associated with risk of AIDS and death, Cox proportional hazards model with care interruptions as time dependent

\begin{tabular}{|c|c|c|c|c|}
\hline & \multicolumn{2}{|c|}{ AIDS free survival* } & \multicolumn{2}{|c|}{ Overall survival $\dagger$} \\
\hline & HR & $95 \% \mathrm{CI}$ & HR & $95 \% \mathrm{CI}$ \\
\hline Medical care interruption & $2 \cdot 54$ & $2 \cdot 10-3 \cdot 09$ & $2 \cdot 65$ & $1 \cdot 94-3 \cdot 61$ \\
\hline \multicolumn{5}{|c|}{ Most probable route of infection } \\
\hline Heterosexual & Ref. & - & Ref. & - \\
\hline Homosexual/bisexual & $0 \cdot 89$ & $0 \cdot 81-0 \cdot 97$ & $0 \cdot 738$ & $0 \cdot 59-0 \cdot 92$ \\
\hline Materno-fetal & $0 \cdot 76$ & $0 \cdot 50-1 \cdot 17$ & $0 \cdot 38$ & $0 \cdot 13-1 \cdot 27$ \\
\hline Blood products/IVDU & $0 \cdot 86$ & $0 \cdot 75-0.99$ & $1 \cdot 03$ & $0 \cdot 81-1 \cdot 31$ \\
\hline Other/unknown & $1 \cdot 39$ & $1 \cdot 16-1 \cdot 67$ & 1.44 & $0 \cdot 90-2 \cdot 30$ \\
\hline \multicolumn{5}{|l|}{ HIV care centre } \\
\hline A & Ref. & - & Ref. & - \\
\hline B & $2 \cdot 51$ & $2 \cdot 09-3 \cdot 03$ & $1 \cdot 59$ & $0 \cdot 99-2 \cdot 56$ \\
\hline $\mathrm{C}$ & $1 \cdot 84$ & $1 \cdot 51-2 \cdot 23$ & $2 \cdot 28$ & $1 \cdot 44-3 \cdot 44$ \\
\hline $\mathrm{D}$ & $1 \cdot 38$ & $1 \cdot 16-1 \cdot 63$ & $1 \cdot 05$ & $0 \cdot 70-1 \cdot 56$ \\
\hline E & $1 \cdot 63$ & $1 \cdot 37-1.94$ & $1 \cdot 57$ & $1 \cdot 04-2 \cdot 37$ \\
\hline $\mathrm{F}$ & $1 \cdot 29$ & $1 \cdot 08-1 \cdot 55$ & $1 \cdot 57$ & $1 \cdot 04-2 \cdot 36$ \\
\hline G & $1 \cdot 27$ & $1 \cdot 07-1 \cdot 51$ & $0 \cdot 99$ & $0 \cdot 66-1 \cdot 47$ \\
\hline Hepatitis co-infection & $1 \cdot 21$ & $1 \cdot 09-1 \cdot 35$ & $1 \cdot 35$ & $1 \cdot 06-1 \cdot 71$ \\
\hline
\end{tabular}

HR, Hazard ratio; CI, confidence interval; IVDU, intravenous drug user.

* From time of HIV diagnosis to the first AIDS defining event or date of censoring;

$\dagger$ From time of HIV diagnosis to the date of death or date of censoring. 
Table 4. Medical care interruptions: description and consequences

\begin{tabular}{|c|c|c|c|c|}
\hline & $N(\%)$ & $\begin{array}{l}\text { VL below } \\
\text { detection at LVBI } \\
N(\%)\end{array}$ & $\begin{array}{l}\text { Detectable } \\
\text { VL at LVBI } \\
N(\%)\end{array}$ & $P$ \\
\hline \multicolumn{5}{|l|}{ Year of LVBI } \\
\hline 2006 & $174(21)$ & $33(19)$ & $141(81)$ & \multirow[t]{6}{*}{$0 \cdot 004$} \\
\hline 2007 & $172(21)$ & $31(18)$ & $141(82)$ & \\
\hline 2008 & $142(17)$ & $29(20)$ & $113(80)$ & \\
\hline 2009 & $142(17)$ & $36(25)$ & $106(75)$ & \\
\hline 2010 & $124(15)$ & $34(27)$ & $90(73)$ & \\
\hline 2011 and first quarter of 2012 & $70(9)$ & $28(54)$ & $42(46)$ & \\
\hline \multicolumn{2}{|l|}{$\begin{array}{l}\text { ART prescription at LVBI, by year of interruption } \\
(\mathrm{Y} / \mathrm{N} ; \% \text { treated })^{*}\end{array}$} & \multicolumn{2}{|c|}{ Among the patients receiving ART } & \\
\hline 2006 & $107 / 67(61 \cdot 6)$ & $32(29 \cdot 9)$ & $75(70 \cdot 1)$ & $0 \cdot 07$ \\
\hline 2007 & $92 / 80(53 \cdot 5)$ & $29(31 \cdot 5)$ & $63(68 \cdot 5)$ & \\
\hline 2008 & $99 / 43(69 \cdot 7)$ & $28(28 \cdot 3)$ & $71(71 \cdot 7)$ & \\
\hline 2009 & $102 / 40(71 \cdot 8)$ & $36(35 \cdot 3)$ & $66(64 \cdot 7)$ & \\
\hline 2010 & $90 / 34(72 \cdot 6)$ & $34(37 \cdot 8)$ & $56(62 \cdot 2)$ & \\
\hline 2011 and first quarter of 2012 & $54 / 16(77 \cdot 1)$ & $28(51 \cdot 8)$ & $26(48 \cdot 2)$ & \\
\hline First AIDS defining event after care resumption & $91(11)$ & 18 & 73 & \\
\hline $\begin{array}{l}\text { Duration of known HIV infection at LBVI } \\
\text { (months), median (IQR) }\end{array}$ & $93 \cdot 5(30 \cdot 5$ to 171$)$ & $138(67$ to 215$)$ & $76(24$ to 163$)$ & $<0 \cdot 001$ \\
\hline Duration of interruption (months), median (IQR) & $22(18$ to 32$)$ & $22(17$ to 31$)$ & $23(18$ to 32$)$ & $0 \cdot 20$ \\
\hline CD4 cell count at LBVI $\left(/ \mathrm{mm}^{3}\right)$, median (IQR) & $434(274$ to 605$)$ & $445(294$ to 632$)$ & $428(268$ to 597$)$ & $0 \cdot 10$ \\
\hline $\begin{array}{l}\text { CD4 cell count at the time of care resumption } \\
\left(/ \mathrm{mm}^{3}\right) \text {, median }(\mathrm{IQR})\end{array}$ & $287(135$ to 478$)$ & $245(107$ to 464$)$ & 298 (143 to 488$)$ & $0 \cdot 28$ \\
\hline $\begin{array}{l}\text { Loss in CD4 cells during interruption }\left(/ \mathrm{mm}^{3}\right) \text {, } \\
\text { median (IQR) }\end{array}$ & $-114(-242$ to -8$)$ & $-161(-334$ to -6$)$ & $-107(-224$ to -8$)$ & $0 \cdot 01$ \\
\hline
\end{tabular}

VL, Viral load; LVBI, last visit before interruption; ART, anti-retroviral therapy.

$* P<0 \cdot 001$.

The mean times from HIV diagnosis to the first AIDS-defining event were 18 and 21 years, respectively for patients with at least one MCI and with UFU, respectively $(P=0 \cdot 0003)$. The mean times from HIV diagnosis to death were 25 and 29 years, respectively for MCI and UFU patients $(P=0 \cdot 09)$. Of patients with at least one MCI, death was HIV-related in $43 \%$ of cases, compared to $17 \cdot 7 \%$ of deaths in patients with UFU $(P=0 \cdot 0007)$. Table 3 shows the results of the proportional Cox hazards models. MCI patients had significantly higher risk of death and AIDS [hazard ratio (HR) 2.64 (95\% CI 1.94-3.61) and HR 2.55 (95\% CI 2.10-3.09), respectively]. Most probable route of infection and HIV care centre were also associated with AIDS-free and overall survival.

The median duration of MCI was 22 months (IQR 18-32). The description of the interruptions and their consequences are shown in Table 4 . With passing years, more patients were receiving ART at the time of last visit before interruption (from 61.6\% in 2006 to $77 \cdot 1 \%$ in $2011, P<0 \cdot 001$ ), meanwhile the proportion of treated patients with detectable VL at the time of interruption decreased from $70 \%$ in 2006 to $48 \%$ in $2011(P=0 \cdot 07)$.

\section{DISCUSSION}

In this large multi-centre cohort we found that MCIs had a deleterious effect for patients, with significant loss in CD4 cell count and increased risk of death and AIDS.

The characteristics of patients with MCI were similar to those previously described in LTFU patients: young age, and absence of ART prescription at the time of interruption [8-10]. Hopefully, the widening of the recommendations to treat each and every patient will allow some decrease in care interruptions. However, prescribing ART is just one step in the care continuum, and efforts are still needed to address the multiplicity of barriers faced by individuals across each step [15]. It is wearisome that in our study, despite greater frequency of ART prescription over the passing years, most of the patients still had detectable VL at the time of MCI. 
We have shown that the proportion of patients with at least one MCI compared to patients with UFU is different between centres. It is important to know that some of the centres have proactive methods for bringing patients back-to-care in case of LTFU $[9,16]$, so it was predictable that they would have greater proportions of back-to-care patients. Those methods can be as simple and cost-effective as phone calls, text messages or e-mails, and should be implemented in all the centres to reduce the proportion of patients with MCIs.

Of the 91 patients who presented with a first AIDS-defining event after care resumption, more than a half returned to care for that very reason. It is noteworthy that most of these events could have been avoided with efficient follow-up. Even if the designs are quite different, they can be compared with the results of the study published by Lee et al. who found that half of acute opportunistic infections were described in patients who were informed of their HIV infection but not seeking care [11].

The impact of MCIs on AIDS-free and overall survival is clear in the multivariate Cox model, even if the Kaplan-Meier estimation failed to show a significant difference between groups regarding overall survival, probably because of the small proportion of deaths. This impact had already been shown in a smaller French cohort in patients in care between 1997 and 2006 [1]. AIDS-related mortality has been decreasing in France from $47 \%$ of all HIV-infected patients' deaths in 2000 to $25 \%$ in 2010 , but the authors underline that this is still high in a country with universal access to care [17]. Without doubt, MCIs play a role in this persistent proportion of AIDS-related deaths.

At the public health level MCIs also have consequences, as at the end of the study period patients with past MCI frequently had less VLs below detection thresholds. It has been published recently that patients who are less likely to stay in care are those who are more likely to be at risk of transmitting HIV to others because more often they do not receive ART and have high VLs [16]. Unfortunately, our results show that these differences are persistent even after care resumption.

The strength of our study lies with the population size, the multicentre design and the long study period; however, this study also has limits. First, the patients we considered to have follow-up interrupted could have been seeking care elsewhere during the considered care interruption. To minimize this potential classification bias, we did not consider interruptions when the first VL obtained after care resumption was below the detectable threshold. Second, due to the retrospective design of the study, we could not assess the reasons why patients interrupted their follow-up at a given time, nor the reason why they came back (apart from the 53 AIDS-defining events concomitant with the back-to-care visit), although this information might be of great importance in designing strategies to limit the phenomenon.

In conclusion, we found that even in the most recent years and in a country with universal access to care and treatment, MCIs remained associated with individual damage. They also represent a threat to the global aim of HIV-incidence reduction by universal treatment access.

\section{APPENDIX. Dat'AIDS Study Group}

P. Enel, V. Obry-Roguet, O. Faucher, S. Bregigeon, I. Poizot-Martin, (Marseille); B. Marchou, P. Massip, E. Bonnet, M. Obadia, M. Alvarez, L. Porte, L. Cuzin, P. Delobel, M. Chauveau, D. Garipuy, I. Lepain, M. Marcel, E. Puntis, K. Sauné (Toulouse); P. Pugliese, C. Ceppi, E. Cua, J. Cottalorda, P. Dellamonica, E. Demonchy, B. Dunais, J. Durant, C. Etienne, S. Ferrando, J. G. Fuzibet, R. Garraffo, K. Risso, V. Mondain, A. Naqvi, N. Oran, I. Perbost, S. Pillet, B. Prouvost-Keller, C. Pradier, S. Wehrlen-Pugliese, E. Rosenthal, S. Sausse, P.M. Roger (Nice); C. Allavena, C. Bernaud, E. Billaud, C. Biron, B. Bonnet, S. Bouchez, D. Boutoille, C. Brunet-Cartier, N. Hall, T. Jovelin, P. Morineau, F. Raffi, V. Reliquet, H. Hue, L. Larmet, So. Pineau (Nantes); A. Cheret, P. Choisy (Tourcoing); Y. Yazdanpanah, C. Duvivier, M.A. Valantin, R. Agher, C. Katlama, Michka Shoai-Tehrani, O. Lortholary, P.H. Consigny, G. Cessot, F. Touam, K. Benhadj (Paris); A. Cabié, S. Abel, S. Pierre-François (Fort de France) ; D. Rey, E. Ebel, P. Fischer, M. Partisani (Strasbourg); C. Chirouze, C. Drobacheff-Thiébaut, J.P. Faller, J.F. Faucher, A. Foltzer, H. Gil, L. Hustache-Mathieu, C. Bourdeaux (Besançon), B. Hoen (Pointe à Pitre)

\section{ACKNOWLEDGEMENTS}

This work did not require any funding.

\section{DECLARATION OF INTEREST}

None. 


\section{REFERENCES}

1. Ndiaye B, et al. Characteristics of and outcomes in HIV-infected patients who return to care after loss to follow-up. AIDS 2009; 23: 1786-1789.

2. Cohen MS, et al. Prevention of HIV-1 infection with early antiretroviral therapy. New England Journal Medicine 2011; 365: 493-505.

3. Henard $\mathbf{S}$, et al. Is total community viral load a robust predictive marker of the efficacy of the TasP strategy? Journal of Acquired Immune Deficiency Syndrome 2012; 61: 400-402.

4. Montaner JS, et al. Association of highly active antiretroviral therapy coverage, population viral load, and yearly new HIV diagnoses in British Columbia, Canada: a population-based study. Lancet 2010; 376: 532-539.

5. CDC. Vital signs: HIV prevention through care and treatment-United States. Morbidity and Mortality Weekly Report 2011; 60: 1618-1623.

6. Cuzin L, et al. Can the 'Seek, test, Treat and Retain' strategy be effective in France ? Journal of Acquired Immune Deficiency Syndrome 2013; 62: e119-e121.

7. Helleberg M, et al. Retention in a public healthcare system with free access to treatment: a Danish nationwide HIV cohort study. AIDS 2012; 26: 741-748.

8. Mocroft A, et al. Loss to follow-up in an international, multicentre observational study. HIV Medicine 2008; 9: 261-9.

9. Ndiaye B, et al. Incidence rate and risk factors for loss to follow-up in HIV-infected patients from five
French clinical centres in Northern France-January 1997 to December 2006. Antiviral Therapy 2009; 14: 567-575.

10. Rebeiro P, et al. Retention among North American HIV-infected persons in clinical care, 2000-2008. Journal of Acquired Immune Deficiency Syndrome 2013; 62: 356-362.

11. Lee M, et al. Comparison of two cohorts of patients presenting with AIDS: patients with previously known HIV diagnoses and true late presenters. Sexually Transmited Infections 2013; 89: 553-6.

12. Pugliese $\mathbf{P}$, et al. A large French prospective cohort of HIV-infected patients: the Nadis Cohort. HIV Medicine 2009; 10: 504-511.

13. 2013 French HIV Expert Group. French 2013 guidelines for antiretroviral therapy of HIV-1 infection in adults. Journal of the International AIDS Society 2014; 17: 19034.

14. Desquilbet L, Meyer L. Time-dependent covariates in the Cox proportional hazards model. Theory and practice [in French]. Revue Epidemiologie Santé Publique 2005; 53: 51-68.

15. McNairy ML, El-Sadr WM. The HIV care continuum: no partial credit given. AIDS 2012; 26: 1735-1738.

16. Cunningham CO, et al. Factors associated with returning to HIV care after a gap in care in New York State. Journal of Acquired Immune Deficiency Syndrome 2014; 66: 419-427.

17. Morlat $\mathbf{P}$, et al. Causes of death among HIV-infected patients in France in 2010 (national survey): trends since 2000. AIDS 2014; 28: 1181-1191. 